\title{
Characterization and use of high surface area activated carbons prepared from cane pith for liquid-phase adsorption
}

\author{
Ru-Ling Tseng a,b,*, Szu-Kung Tseng ${ }^{\mathrm{a}}$ \\ a Graduate Institute of Environmental Engineering, National Taiwan University, Taiwan \\ ${ }^{\mathrm{b}}$ Department of Safety, Health and Environmental Engineering, National United University, Miao-Li 360, Taiwan
}

Received 31 July 2005; received in revised form 11 December 2005; accepted 28 December 2005

Available online 20 February 2006

\begin{abstract}
Carbonaceous adsorbents with controllable surface areas were chemically activated with $\mathrm{KOH}$ at $780{ }^{\circ} \mathrm{C}$ from char that had been carbonized from cane pith at $450{ }^{\circ} \mathrm{C}$. The pore properties including the BET surface area, pore volume, pore size distribution, and mean pore diameter of these activated carbons were characterized and derived using the $t$-plot method based on $\mathrm{N}_{2}$ adsorption isotherms. The activated cane pith carbons, with $\mathrm{KOH} / \mathrm{char}$ ratios of 2-6, exhibited BET surface areas ranging from 912 to $2299 \mathrm{~m}^{2} \mathrm{~g}^{-1}$. The scanning electron microscopic (SEM) observations revealed that the surface morphology of honeycombed holes on all activated cane pith carbons was significantly influenced by the KOH/char ratio. The adsorption kinetics and equilibrium isotherms of acid blue 74, methylene blue, basic brown 1, $p$-nitrophenol, $p$-chlorophenol, $p$-cresol, and phenol from water at $30^{\circ} \mathrm{C}$ on the activated carbons were studied. The adsorption kinetics were suitably described by a simplified kinetic model, the Elovich equation. All adsorption equilibrium isotherms were in agreement with the Langmuir equation, and were used to compare the covered area $\left(S_{\mathrm{c}} / S_{\mathrm{p}}\right)$ of the activated carbons at different $\mathrm{KOH} /$ char ratios. The high-surface-area activated carbons were proven to be promising adsorbents for pollution control and for other applications.
\end{abstract}

(C) 2006 Elsevier B.V. All rights reserved.

Keywords: Activated carbons; KOH activation; Cane piths; Pore properties; Adsorption

\section{Introduction}

Cane pith is a mass agricultural waste in tropical and subtropical regions including Taiwan. Besides being utilized as fuel and compost, a small percentage of cane pith is used as industrial raw material for low price products, such as cane board, soil conditioner, etc. Activated cane pith activated carbons (ACs) have been produced by some researchers. The ACs of surface areas of between 565 and $607 \mathrm{~m}^{2} \mathrm{~g}^{-1}$ were obtained by steam activation $[1,2]$; a surface area of less than $800 \mathrm{~m}^{2} \mathrm{~g}^{-1}$ was obtained by chemical activation using $\mathrm{ZnCl}_{2}$ [3]. These results emphasize the difficulty of producing high surface area ACs from cane pith.

Activated carbon is an important material and has been widely used in various industrial applications [4-6]. In general, carbon with a unique pore size distribution is due to the differences in precursors and treatments [7]. In our laboratory, a series of stud-

\footnotetext{
* Corresponding author. Tel.: +886 37 381775; fax: +886 37333187 .

E-mail address: trl@nuu.edu.tw (R.-L. Tseng).
}

ies were conducted to prepare porous carbons from various wood wastes and fruit shells using physical (steam) and chemical activation $(\mathrm{KOH})$ methods. These carbons were then evaluated to their full potential for application in industrial pollution control and supercapacitor $[4,8-11]$. The aim of this work was to prepare high surface area carbons with controllable pore size from carbonized cane pith (that is, char) by $\mathrm{KOH}$ activation, and to compare their physical properties and adsorption performance. The physical properties studied include the BET surface area, pore size distribution, and pore volume. The kinetics and equilibrium of the adsorption of dyes and phenols from water were also investigated.

\section{Materials and methods}

\subsection{Preparation of the carbons by steam activation}

In this research, edible red sugar cane (Saccharum officinarum), popular in Taiwan, was used. The raw material for the activated carbon was obtained after it was peeled and squeezed. 


\begin{tabular}{|c|c|}
\hline \multicolumn{2}{|c|}{ Nomenclature } \\
\hline$C_{0}$ & $\begin{array}{l}\text { initial solute concentration in the aqueous phase } \\
(\mathrm{mM})\end{array}$ \\
\hline$C_{\mathrm{e}}$ & $\begin{array}{l}\text { solute concentration in the aqueous phase at equi- } \\
\text { librium }(\mathrm{mM})\end{array}$ \\
\hline$C_{t}$ & $\begin{array}{l}\text { solute concentration in the aqueous phase at time } \\
t(\mathrm{mM})\end{array}$ \\
\hline$d_{\mathrm{p}}$ & mean pore diameter $(\mathrm{nm})$ \\
\hline$K_{\mathrm{L}}$ & Langmuir constant defined in Eq. (8) $\left(\mathrm{m}^{3} \mathrm{~g}^{-1}\right)$ \\
\hline$q_{\mathrm{e}}$ & amount of adsorption at equilibrium $\left(\mathrm{mol} \mathrm{kg}^{-1}\right)$ \\
\hline$q_{\text {mon }}$ & $\begin{array}{l}\text { amount of adsorption corresponding to mono- } \\
\text { layer coverage }\left(\mathrm{mol} \mathrm{kg}^{-1}\right)\end{array}$ \\
\hline$q_{t}$ & amount of adsorption at time $t\left(\mathrm{~mol} \mathrm{~kg}^{-1}\right)$ \\
\hline$S_{\mathrm{c}}$ & $\begin{array}{l}\text { adsorbate coverage per unit gram of activated car- } \\
\text { bon }\left(\mathrm{m}^{2} \mathrm{~g}^{-1}\right)\end{array}$ \\
\hline$S_{\text {ext }}$ & external surface area of the adsorbent $\left(\mathrm{m}^{2} \mathrm{~g}^{-1}\right)$ \\
\hline$S_{\text {micro }}$ & $\begin{array}{l}\text { surface area of adsorbent due to micropore } \\
\left(\mathrm{m}^{2} \mathrm{~g}^{-1}\right)\end{array}$ \\
\hline$S_{\mathrm{p}}$ & $\begin{array}{l}\text { BET specific surface area of adsorbent particles } \\
\left(\mathrm{m}^{2} \mathrm{~g}^{-1}\right)\end{array}$ \\
\hline$t$ & time $(\min )$ \\
\hline$V_{\text {micro }}$ & micropore volume $\left(\mathrm{cm}^{3} \mathrm{~g}^{-1}\right)$ \\
\hline$V_{\text {pore }}$ & total pore volume $\left(\mathrm{cm}^{3} \mathrm{~g}^{-1}\right)$ \\
\hline$W / V$ & dose of the dry adsorbent used $\left(\mathrm{kg} \mathrm{m}^{-3}\right)$ \\
\hline$Y$ & yield of the carbon product (\%) \\
\hline
\end{tabular}

The cane pith was dried at $110^{\circ} \mathrm{C}$ for $24 \mathrm{~h}$. It then was placed in a sealed ceramic oven and heated at a rate of $5^{\circ} \mathrm{C} \mathrm{min}^{-1}$ increase from room temperature to $450^{\circ} \mathrm{C}$. At the same time, $\mathrm{N}_{2}$ was poured into the oven at a rate of $3 \mathrm{dm}^{3} \mathrm{~min}^{-1}$ for $1.5 \mathrm{~h}$. Under such oxygen-deficient conditions, the cane pith was thermally decomposed to porous carbonaceous materials and hydrocarbon compounds. This was the carbonization step. The chemical composition (wt.\%) of the char was $62.10 \%$ of $\mathrm{C}, 3.43 \%$ of $\mathrm{H}$, $1.22 \%$ of $\mathrm{N}$, and $0.26 \%$ of $\mathrm{S}$.

A char/cane pith ratio of 0.30 was obtained after carbonization. The cane pith char was removed, crushed, and sieved to a uniform size ranging from 0.83 to $1.65 \mathrm{~mm}$. The powder was divided into six stainless steel beakers, mixed with water and $\mathrm{KOH}$ at a constant water/char weight ratio of 14 and $\mathrm{KOH} /$ char weight ratios of $0,2,3,4,5$, and 6 . After having being dried at $130^{\circ} \mathrm{C}$ for $24 \mathrm{~h}$, the chars were placed in a sealed ceramic oven and heated at a rate of $10^{\circ} \mathrm{C} \mathrm{min}^{-1}$ to $780^{\circ} \mathrm{C}$. The oven was kept at this temperature for $1 \mathrm{~h}$. At the same time, $\mathrm{N}_{2}$ gas was flowed into the oven at a rate of $3 \mathrm{dm}^{3} \mathrm{~min}^{-1}$. The products were cooled to room temperature and washed with deionized water. Samples were then poured into beakers containing $250 \mathrm{~cm}^{3}$ of $0.1 \mathrm{M} \mathrm{HCl}$ and stirred for $1 \mathrm{~h}$. The samples were finally washed with hot water until the $\mathrm{pH}$ of the washing solution reached 6-7 [12]. The carbons obtained from cane pith by $\mathrm{KOH}$ activation with $\mathrm{KOH} / \mathrm{char}$ weight ratios $\left(R_{\mathrm{KOH}}\right)$ of $0,2,3,4,5$, and 6 were named CPKC0, CPKC2, CPKC $3, \mathrm{CPKC} 4, \mathrm{CPKC} 5$, and CPKC6, respectively.
High surface area activated carbons were prepared with a twostage $\mathrm{KOH}$ method in this study. When ordinary plant material is immersed in $\mathrm{KOH}$ solution at temperature more than $100^{\circ} \mathrm{C}$, fiber corrodes and disappears, high surface area activated carbon is not easy to prepare. In this study, char, obtained from carbonization of cane pith, was immersed in a $\mathrm{KOH}$ solution, the char pores were filled with $\mathrm{KOH}$. Reactions took place in the char under smelted $\mathrm{KOH}$ at temperatures more than $780^{\circ} \mathrm{C}$, and high surface activated carbon was obtained.

\subsection{Measurement of physical properties}

The yield $(Y)$ was defined as the weight ratio of the final carbons to the dried raw material. The BET surface area of the carbon $\left(S_{\mathrm{p}}\right)$ was measured from $\mathrm{N}_{2}$ adsorption isotherms at $77 \mathrm{~K}$ with a sorptiometer (Porous Materials, BET-202A). Prior to this measurement, the samples were dried overnight in an oven at $130^{\circ} \mathrm{C}$ and then quickly placed in the sample tube. After that, the tube was heated to $230^{\circ} \mathrm{C}$ and then evacuated for $4 \mathrm{~h}$ until the pressure was less than $10^{-4}$ Torr. The total pore volume ( $V_{\text {pore }}$ ) was deduced from $\mathrm{N}_{2}$ adsorption isotherms according to the manufacturer's software, and pore size distribution by volume $\left(\mathrm{d} V_{\text {pore }} / \mathrm{d} d_{\mathrm{p}}\right)$ was derived from the BJH theory [8]. The micropore volume $\left(V_{\text {micro }}\right)$ and external surface area $\left(S_{\text {ext }}\right)$ were deduced using the $t$-plot method [13]. The surface area corresponding to the micropores $\left(S_{\text {micro }}\right)$ was obtained from the difference between $S_{\mathrm{p}}$ and $S_{\text {ext }}$ [2]. In some researches, when the BET surface area was measured, adsorption capacities of high surface area activated carbons on $\mathrm{N}_{2}$ and $\mathrm{CO}_{2}$ were both investigated simultaneously in BET surface area measurements in some research $[14,15]$. It was found that there was a significant difference between the adsorption capacities. This is because nitrogen has been observed to condense in mesopores [16]. In this research, activated carbons of CPKC5 and CPKC6, with characteristics of mesoporosity, were used for BET surface area measurements with nitrogen, which led to higher surface area estimation. This problem is yet to be solved.

\subsection{Procedures for adsorption experiments}

Seven analytical-reagent-grade solutes including AB74 (466.4 $\left.\mathrm{g} \mathrm{mol}^{-1}\right)$, BB1 (419.4 $\left.\mathrm{g} \mathrm{mol}^{-1}\right), \mathrm{MB}\left(284.3 \mathrm{~g} \mathrm{~mol}^{-1}\right)$, $p$-NP $\quad\left(138.2 \mathrm{~g} \mathrm{~mol}^{-1}\right), \quad p$-CP $\quad\left(128.6 \mathrm{~g} \mathrm{~mol}^{-1}\right), \quad p$-cresol $\left(108.2 \mathrm{~g} \mathrm{~mol}^{-1}\right)$, and phenol $\left(94.1 \mathrm{~g} \mathrm{~mol}^{-1}\right)$, molecular weights ranging from 94.1 to $466.4 \mathrm{~g} \mathrm{~mol}^{-1}$, were used to observe the pore sizes of different carbons, and the relation of the adsorption kinetic and the adsorption capacity with pore size of adsorbent. The molecular structures and the characteristics of the dyes are illustrated in the literature [27]. Adsorption types are determined by molecular structures. The AB74 is adsorbed two dimensionally, BB1 and MB one dimensionally. The covered areas of adsorption sites $0.62,0.294$, and $0.244 \mathrm{~nm}^{2}$ [27], respectively, for AB74, BB1, and MB.

In adsorption runs, a fixed amount of activated carbon $(0.05 \mathrm{~g})$ and $100 \mathrm{~cm}^{3}$ of an aqueous solution were placed in a $250 \mathrm{~cm}^{3}$ glass-stoppered flask, which was shaken at $130 \mathrm{rpm}$ for 5 days using a thermostated shaker bath (Firstes Model B603, Taiwan). 
For the investigations into the adsorption characteristics of various kinds of carbons on a single solute, the concentrations of dyes and phenols in the aqueous phase were analyzed using a Hitachi UV-vis spectrophotometer (Model U-2001) at appropriate wavelength.

Kinetic experiments were carried out in a Pyrex glass vessel $100 \mathrm{~mm}$ in inner diameter, $130 \mathrm{~mm}$ in height, and fitted with four glass baffles (each $10 \mathrm{~mm}$ in width). The aqueous solution $\left(0.6 \mathrm{dm}^{3}\right)$ with $0.6 \mathrm{~g}$ carbons was agitated at $500 \mathrm{rpm}$ using a Cole-Parmer Servodyne agitator with a six-flat-blade impeller (12 $\mathrm{mm}$ high and $40 \mathrm{~mm}$ wide). The stirring speed had no effect on the adsorption when it was higher than $500 \mathrm{rpm}$. When carbons were added to the vessel, the time recording was started. The vessel was immersed in a water bath kept at $30^{\circ} \mathrm{C}$. Aqueous samples $\left(5 \mathrm{~cm}^{3}\right)$ were taken from the solution at preset time intervals and the concentrations were analyzed. The amount of adsorption at time $t, q_{t}\left(\mathrm{~mol} \mathrm{~kg}^{-1}\right)$, was calculated by:

$q_{t}=\frac{\left(C_{0}-C_{t}\right) V}{W}$

where $C_{0}$ and $C_{t}$ are the liquid concentrations $\left(\mathrm{mol} \mathrm{m}^{-3}\right)$ at the beginning and at time $t$, respectively, and $W / V$ is the dose of dried carbon $\left(1 \mathrm{~g} \mathrm{dm}^{-3}\right)$. The experiment error was mostly within $4 \%$.

For the adsorption equilibrium experiments, $0.05 \mathrm{~g}$ carbon was well dispersed in $0.1 \mathrm{dm}^{3}$ aqueous solution in a $0.25 \mathrm{dm}^{3}$ flask and stirred for 4 days in a water bath (Haake Model K-F3) at $30^{\circ} \mathrm{C}$. Preliminary tests showed that adsorption was complete after 3 days. After filtration with glass fiber the concentrations were analyzed. Each experiment was repeated at least three times under identical conditions. The amount of adsorption at equilibrium, $q_{\mathrm{e}}\left(\mathrm{mol} \mathrm{kg}^{-1}\right)$, was calculated according to Eq. (2):

$q_{\mathrm{e}}=\frac{\left(C_{0}-C_{\mathrm{e}}\right) V}{W}$

where $C_{\mathrm{e}}$ is the liquid concentrations $\left(\mathrm{mol} \mathrm{m}^{-3}\right)$ at the equilibrium. The experiment errors were mostly within $4 \%$.

\section{Results and discussion}

\subsection{Physical properties of $\mathrm{KOH}$-activated carbons}

Fig. 1 shows the adsorption/desorption isotherms of $\mathrm{N}_{2}$ for carbons prepared at various $R_{\mathrm{KOH}}$ values. The slope of curves gradually increased with increased $R_{\mathrm{KOH}}$. The adsorbed volume for CPKC6 increased with increased $P / P_{0}$, indicating a wider pore size distribution; the isotherm for $\mathrm{CPKC} 2$ seemed to be Langmuir type [17]. The initial (steepest) part of the isotherm represents the micropore filling (rather than surface coverage) and a low slope of the plateau is indicative of multilayer adsorption on the external surface. Thus, CPKC2 is considered to be microporous solid with a relatively small external area. This statement can be confirmed from pore size distributions (Fig. 2).

According to the definition by IUPAC, the adsorbent pores were classified into three groups: micropore (diameter $<2 \mathrm{~nm}$ ), mesopore $(2-50 \mathrm{~nm})$, and macropore $(>50 \mathrm{~nm})$. The pores of CPKC2 were mainly less than $2 \mathrm{~nm}$, and the pores of CPKC6 were mainly less than $4 \mathrm{~nm}$. In general, micropores usually

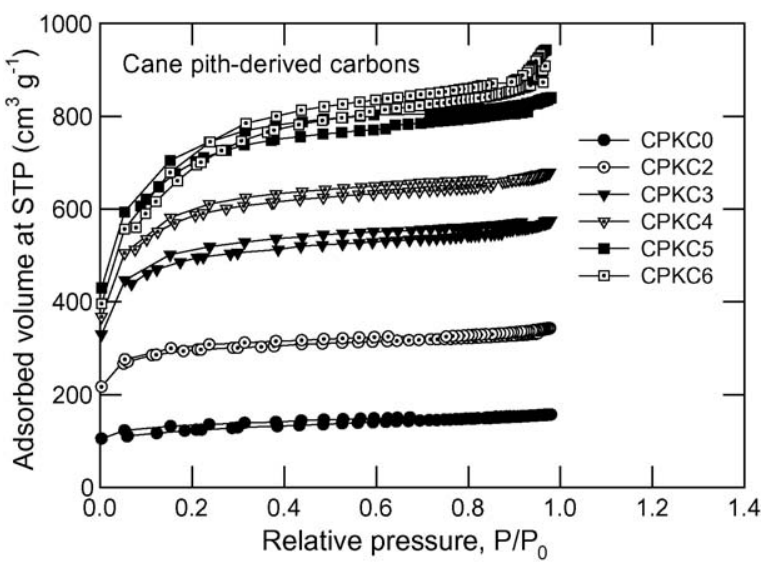

Fig. 1. Adsorption/desorption isotherms of $\mathrm{N}_{2}$ at $77 \mathrm{~K}$ on $\mathrm{KOH}$ activated carbons derived from cane pith $(\mathrm{KOH} /$ char ratio $0(\mathbf{O}), 2(\bigcirc), 3(\boldsymbol{\nabla}), 4(\nabla), 5(\mathbf{a})$, and $6(\square)$, respectively).

account for over $95 \%$ of the total surface area of common activated carbons [3]. This was the case for CPKC2. CPKC6, on the other hand, had both micropores and mesopores.

Table 1 shows the physical properties including $S_{\mathrm{p}}, S_{\text {micro }} / S_{\mathrm{p}}$, $V_{\text {pore }}, V_{\text {micro }} / V_{\text {pore }}, d_{\mathrm{p}}$, and $Y$. The $S_{\mathrm{p}}$ values of $\mathrm{KOH}$-activated carbons gradually increased with increased $R_{\mathrm{KOH}}$. These results agree with those reported earlier $[13,18]$. The maximum $S_{\mathrm{p}}$ for the present carbon $\left(2299 \mathrm{~m}^{2} \mathrm{~g}^{-1}\right)$ was larger than that of any commercially available carbon [19]. Moreover, the carbons prepared from apricot stone, grape seed, and cherry stone by steam activation had an $S_{\mathrm{p}}$ value of 1175,487 , and $836 \mathrm{~m}^{2} \mathrm{~g}^{-1}$, respectively [20]. The largest $S_{\mathrm{p}}$ value recorded for agricultural and wood wastes was $2150 \mathrm{~m}^{2} \mathrm{~g}^{-1}$, which was obtained when wood flour was mixed and activated with 2.4 times of $\mathrm{H}_{3} \mathrm{PO}_{4}$ and a stream of $\mathrm{N}_{2}$ [21].

The micropore areas, $S_{\text {micro }} / S_{\mathrm{p}}$, ranged for CPKC2 to CPKC5 from 0.89 to 0.92 , which were larger than those for CPKC6 and CPST84 (0.84 and 0.87 ). The micropore volumes, $V_{\text {micro }} / V_{\text {pore }}$, were between 0.75 and 0.79 for $\mathrm{CPKC} 2$ to $\mathrm{CPKC} 5$, which were also much larger than those for CPKC6 and CPST84 (0.63 and 0.69). These results indicate that CPKC 2 to CPKC5 facilitated the formation of micropores, as clearly shown in Fig. 2. The carbons of CPKC6 and CPST84 had larger pore sizes $\left(d_{\mathrm{p}}=2.53\right.$ and

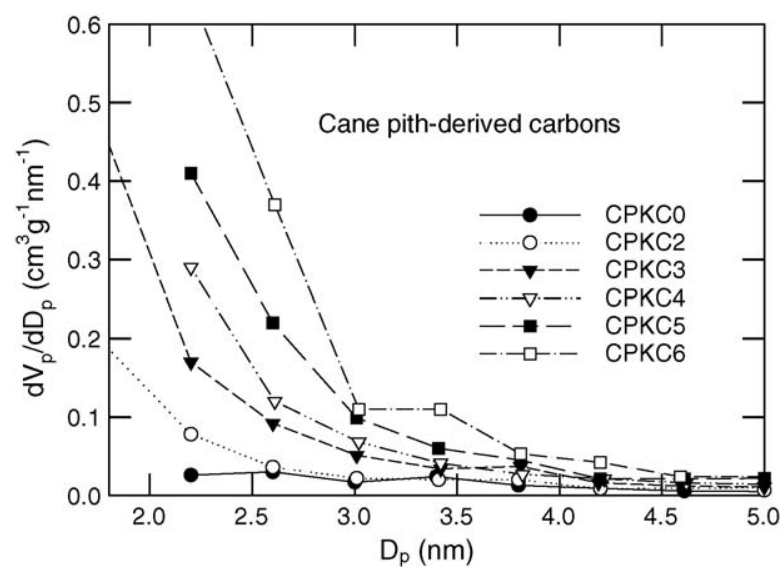

Fig. 2. Pore size distribution of $\mathrm{KOH}$ activated carbons derived from cane pith. 
Table 1

Physical properties of carbons derived from cane pith using $\mathrm{KOH}$ and steam activation

\begin{tabular}{|c|c|c|c|c|c|c|c|}
\hline$\overline{\text { Carbon }}$ & $T_{\mathrm{A}}\left({ }^{\circ} \mathrm{C}\right)$ & $S_{\mathrm{p}}\left(\mathrm{m}^{2} \mathrm{~g}^{-1}\right)$ & $S_{\text {micro }} / S_{\mathrm{p}}(\%)$ & $V_{\text {pore }}\left(\mathrm{cm}^{3} \mathrm{~g}^{-1}\right)$ & $V_{\text {micro }} / V_{\text {pore }}(\%)$ & $d_{\mathrm{p}}(\mathrm{nm})$ & $\overline{Y(\%)}$ \\
\hline СРКC0 & 780 & 391 & & 0.24 & & 2.48 & 12.0 \\
\hline СРКС2 & 780 & 912 & 91.8 & 0.53 & 78.9 & 2.32 & 7.9 \\
\hline CPKC3 & 780 & 1518 & 90.8 & 0.89 & 78.0 & 2.34 & 7.9 \\
\hline CPKC5 & 780 & 2207 & 89.1 & 1.29 & 75.0 & 2.35 & 8.2 \\
\hline СРКС6 & 780 & 2299 & 84.4 & 1.45 & 62.7 & 2.53 & 7.4 \\
\hline $\mathrm{CPST}_{84^{\mathrm{a}}}$ & 840 & 607 & 86.9 & 0.45 & 68.8 & 2.94 & 8.7 \\
\hline
\end{tabular}

${ }^{\text {a }}$ Cane pith activated carbon by steam activation [2].

$2.94 \mathrm{~nm})$ than those of CPKC2 to CPKC5 $\operatorname{did}(2.32-2.35 \mathrm{~nm})$. The $d_{\mathrm{p}}$ values of $2.1,2.4,1.5$, and $2.4 \mathrm{~nm}$ were actually reported for steam-activated carbons derived from coconut shell, palm seed, bagasse, and plum kernels, respectively $[4,17,18]$.

As shown in Table $1, S_{\mathrm{p}}$ gradually increased from 912 to $2207 \mathrm{~m}^{2} \mathrm{~g}^{-1}$, but $V_{\text {micro }} / V_{\text {pore }}$ slightly reduced from 0.79 to 0.76 when $R_{\mathrm{KOH}}$ changed from 2 to 5 . This is probably due to interior etching during $\mathrm{KOH}$ activation [22]. For the carbons activated by $\mathrm{KOH}, \mathrm{ZnCl}_{2}$, or $\mathrm{H}_{3} \mathrm{PO}_{4}$, it is noted that the $S_{\mathrm{p}}$ would increase with an increased dose of chemicals, but the $V_{\text {micro }} / V_{\text {pore }}$ would not always increase proportionally $[18,23,24]$. In the case of coconut shells, the $S_{\mathrm{p}}$ values of 1017,1355 , and $1510 \mathrm{~m}^{2} \mathrm{~g}^{-1}$ were obtained when the $\mathrm{ZnCl}_{2} /$ shell ratios equaled $0.25,0.5$ and 0.75 , respectively [18], but $V_{\text {micro }} / V_{\text {pore }}$ equaled $0.82,0.86$, and 0.86 , respectively. In another study, $V_{\text {micro }} / V_{\text {pore }}$ increased rapidly when the $\mathrm{ZnCl}_{2} /$ shell ratio increased from 1 to 3 [25]. The latter case is not due to the interior etching process. When wood was mixed with $\mathrm{H}_{3} \mathrm{PO}_{4}$ and stirred with streams of steam and $\mathrm{N}_{2}$, respectively, the $V_{\text {micro }} / V_{\text {pore }}$ values of 0.66 and 0.69 were obtained $[21,25]$. Activation reactions are complex for char immersed in solutions of various $\mathrm{KOH}$ ratios. It was found that they could be classified into two groups. The first group includes those from lower $\mathrm{KOH} / \mathrm{char}$ ratios. The surface areas of this group increase with increased $\mathrm{KOH} / \mathrm{char}$ ratios, and their $V_{\text {micro }} / V_{\text {pore }}$ values are almost unchanged. This indicates that both surface pyrolysis and interior etching processes occur simultaneously during the preparation of this group of activated carbons [26]. Data in Table 1 of this study show that CPKC2, $\mathrm{CPKC} 3$, and $\mathrm{CPKC} 4$ belong to this group. The other group includes those from higher $\mathrm{KOH} /$ char ratios. Their $V_{\text {micro }} / V_{\text {pore }}$ values decrease with increased $\mathrm{KOH} / \mathrm{char}$ ratios. The soaking of $\mathrm{KOH}$ into the interior of holes favors the development of micropores and mesopores [26]. Data in Table 1 of this study show that CPKC5 and CPKC6 belong to this group. $V_{\text {micro }} / V_{\text {pore }}$ values are decreased when $V_{\text {pore }}$ is increased.

The yields $(Y)$ for $\mathrm{KOH}$-activated carbons range from 7.2 to $8.2 \%$, which approach those of steam-activated carbons $(8.7 \%)$. In a previous study, firwood and corncob were the raw materials.
When $\mathrm{KOH} / \mathrm{char}$ ratios were from 1 to 6 , yields were from 24.9 to $14.9 \%$ and from 22.3 to $15.95 \%$, respectively [26,24]. But, in this study, when $\mathrm{KOH} /$ char ratios were from 2 to 6 , yields were in the range between 7.4 and $8.2 \%$, different from those of both previously used raw materials. Two possible reasons: first, when raw materials mass transformed into char, the yields were 36 and $35.7 \%$, respectively, for firwood and corncob, and 30\% for cane pith in this study, about $6 \%$ than those of previous raw materials, indicating more of the volatile ingredient, tar, than contained in cane pith (plant tar can be used in medicine, health, and cosmetics). Second, in column 3 of Table 2 are the products of ash ratios and yield (called initial ash). They indicate the ash quantities of carbons at various conditions when calculated as initial precursors. Theoretically, all data of initial ashes of carbons under various conditions should be equal. The data show that initial ashes of cane pith and char are equal, which is in agreement with the theory. The reason is that acid soluble materials (ash) contained in CPKC2 were removed from the carbon when it was washed with acid thus lowering the ash mass as well as yield.

Fig. 3 shows that $S_{\mathrm{p}}$ and $V_{\text {pore }}$ were linearly varied with $R_{\mathrm{KOH}}$ as:

$S_{\mathrm{p}}=363+346 R_{\mathrm{KOH}}$

$V_{\text {pore }}=0.146+0.224 R_{\mathrm{KOH}}$

and the $Y$ values were kept nearly constant at 0.08 , independent of $R_{\mathrm{KOH}}$ values.

\subsection{SEM observations}

Fig. 4 shows the SEM photographs of four kinds of carbons. There were significant differences among the carbons of char, PCKC0, PCKC2, and PCKC6. The photos show that there were semi-transparent, silk-like, thin membranes outside the honeycomb hole openings of the char; the thin membranes outside the honeycomb hole openings of CPKC0 were less because of high temperature activation; the thin membranes outside the honeycomb hole openings of $\mathrm{CPKC} 2$ made it become porous look like

Table 2

Ash content

\begin{tabular}{lllllrrr}
\hline & Cane pith & Char & CPKC2 & CPKC3 & CPKC4 & CPKC5 & CPKC6 \\
\hline Ash ratio (wt.\%) & 2.74 & 9.23 & 12.99 & 21.21 & 35.84 & 37.90 & 40.34 \\
Ash/cane pith (wt.\%) & 2.74 & 2.77 & 1.03 & 1.68 & 2.58 & 3.11 & 2.99 \\
\hline
\end{tabular}




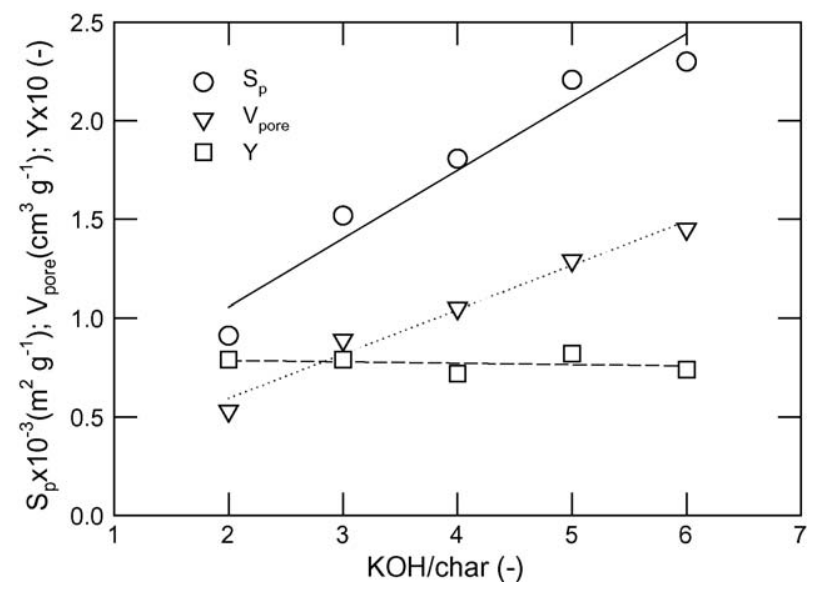

Fig. 3. The yield $(Y)$, total pore volume $\left(V_{\text {pore }}\right)$, and BET surface area $\left(S_{\mathrm{p}}\right)$ of the activated carbons prepared from cane pith at different $\mathrm{KOH} / \mathrm{char}$ ratios.

a sponge because of having been under both high temperature activation and $\mathrm{KOH}$ etching; and the thin membranes outside the honeycomb hole openings of CPKC6 disappeared and the hole walls became thicker. The activation of CPKC6 by $\mathrm{KOH}$ was primarily because of catalytic reactions; thus, carbons smelted at higher $R_{\mathrm{KOH}}(>6)$ and $780^{\circ} \mathrm{C}$. This made the interior of the holes expand uniformly as in flour fermentation. These results agree with those reported earlier [26,27].

The data of column 2 in Table 2 are the ash ratios of cane pith, char, and various kinds of activated carbons. The data show that ash ratios are increase with increased $\mathrm{KOH} /$ char ratios. Called initial ashes data in column 3 of Table 2 are the products of ash ratios and yields. They indicate the ash quantities of carbons under various conditions when calculated as initial pre-cursors. Theoretically, all data of initial ashes of carbons under various conditions should be equal. The data show that initial ashes of cane pith and char are equal, which is in agreement with the theory; that is, the ash masses of carbons were not lost during carbonization. The initial ash of CPKC2 is lower and those of CPKC5 and CPKC6 are higher than the theory value. The reason is that acid soluble materials (ash) contained in CPKC2 were removed from the carbon when it was washed with acid, thus lowering the ash mass. Furthermore, observation revealed that the ash colors of cane pith and char were both pure white, while those of CPKC2 to CPKC6 gradually changed from white to gray black. This is because, at higher $\mathrm{KOH}$ ratios, ash and carbon were smelted and combined with each other under $\mathrm{KOH}$ activation. SEM photos of Fig. 4(a) and (b) show the surface variations of activated carbons. It proves that this part of carbon will not be volatilized or oxidized. This is the reason why the initial ashes of CPKC5 and CPKC6 were higher than the theoretical value.

\subsection{Adsorption kinetics-Elovich equation}

The time profiles for the adsorption of dyes and phenols on various carbons at $30^{\circ} \mathrm{C}$ are shown in Fig. 5. Carbons activated by $\mathrm{KOH}$, although between 500 and $900^{\circ} \mathrm{C}$, still contained many functional groups [28]. The presence of various

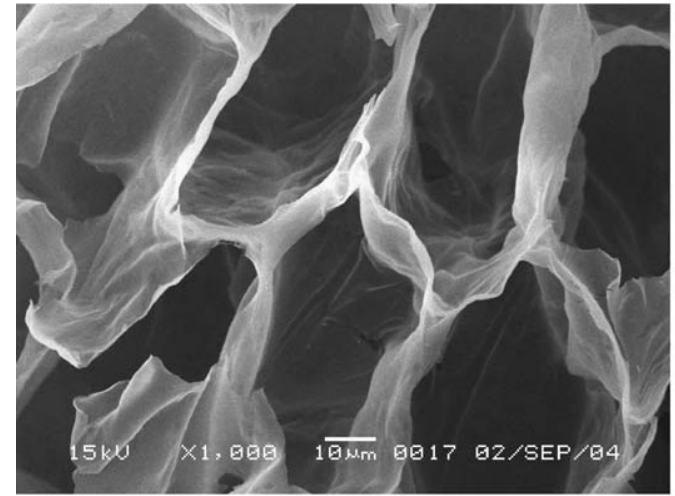

(a)

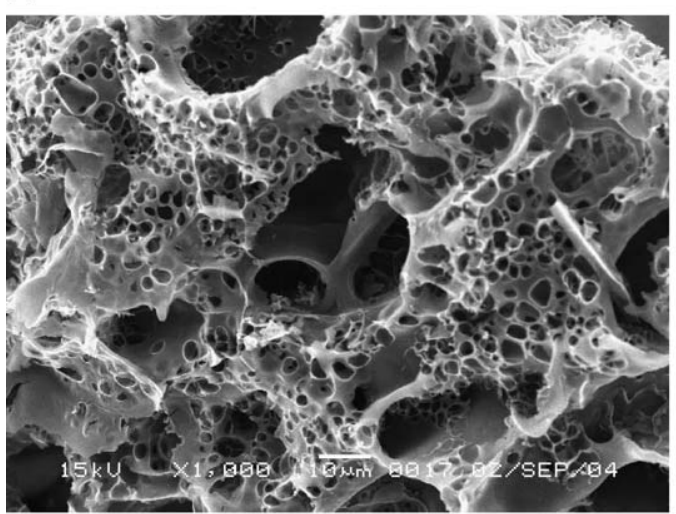

(c)
CPKC2

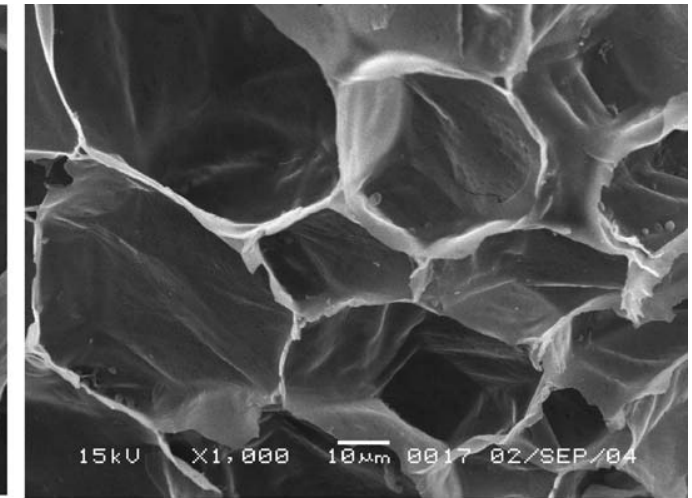

(b)

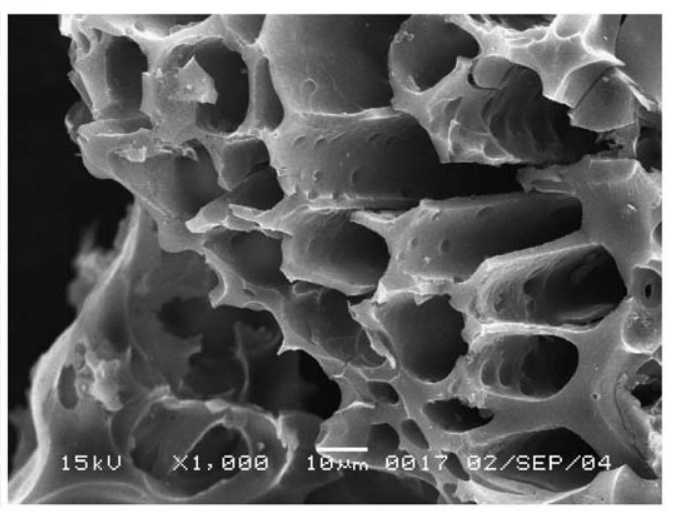

(d)
C PKC6

Fig. 4. Observations with SEM: (a) char, (b) CPKC0, (c) CPKC2, and (d) CPKC6. 

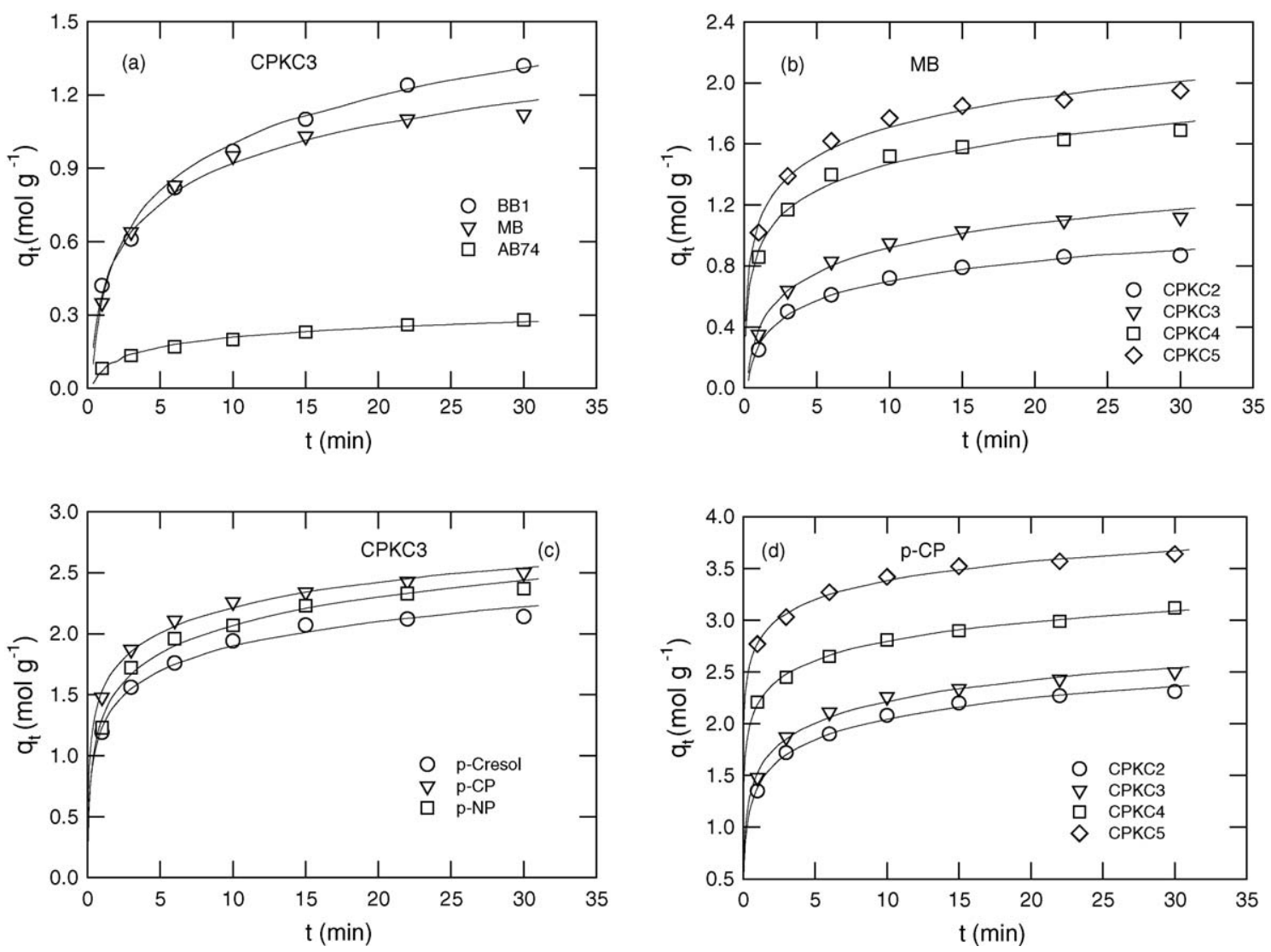

Fig. 5. Adsorption kinetics of (a) dyes on $\mathrm{CPKC} 3$, (b) $\mathrm{MB}$ on $\mathrm{KOH}$-activated carbons, (c) phenols on $\mathrm{CPKC} 3$, and (d) $p$ - $\mathrm{CP}$ on $\mathrm{KOH}$-activated cane pith carbons at $30^{\circ} \mathrm{C}$. The curves were calculated using the Elovich equation. Dyes, $C_{0}=2 \mathrm{~mol} \mathrm{~g}^{-1}$; phenols, $C_{0}=4 \mathrm{~mol} \mathrm{~g}^{-1}$.

functional groups on the carbon surface (e.g. carboxylic, carbonyl, hydroxyl, ether, quinone, lactone, anhydride, etc.) implies that there were many types of solute-adsorbent interactions [29]. Any kinetic or mass transfer expression is likely to be global.

In reactions involving the chemisorption of gases on a solid surface without desorption of the products, the rate decrease with time due to an increase in surface coverage. One of the most useful models for describing such activated chemisorption is the Elovich equation [30].

$\frac{\mathrm{d} q_{t}}{\mathrm{~d} t}=a \exp \left(-b q_{t}\right)$

where $a$ and $b$ are constants during any experiment. The constant, $a$, is regarded as the initial rate because $\left(\mathrm{d} q_{t} / \mathrm{d} t\right)$ approaches $a$ when $q_{t}$ approaches 0 .

Given that $q_{t}=q_{t}$ at $t=t$ and $q_{t}=0$ at $t=0$, the integrated form of Eq. (5) is:

$q_{t}=(1 / b) \ln \left(t+t_{0}\right)-(1 / b) \ln t_{0}$

where $t_{0}=1 / a b$. If $t$ is much larger than $t_{0}$, Eq. (6) can be simplified as:

$q_{t}=(1 / b) \ln (a b)+(1 / b) \ln t$

The validity of Eq. (7) is checked by the linear plot of $q_{t}$ versus $\ln t$ (not shown). Fig. 5(a)-(d) shows the curves of adsorption kinetics for various dyes and phenols on the various activated carbons studied being the results of the analysis values of the
Elovich equation. Fig. 5(a) shows the adsorption curves of BB1, $\mathrm{MB}$, and $\mathrm{AB} 74$ on CPCK3. In the case of $\mathrm{BB} 1$ and $\mathrm{MB}, q_{t}$ values rise steeply at the beginning of adsorption, and then more gradually; $q_{t}$ values still increase after $30 \mathrm{~min}$. The adsorption curve for AB74 approaching level rises slowly. These results agree with those of earlier studies [27]. Fig. 5(b) shows the adsorption curves of $\mathrm{MB}$ on $\mathrm{CPKC} 2, \mathrm{CPKC} 3, \mathrm{CPKC} 4$, and CPKC5, respectively. These curves are similar; but the $q_{t}$ values increase with increased $R_{\mathrm{KOH}}$ values. Fig. 5(c) shows the adsorption curves of $p$-cresol, $p$-CP, and $p$-NP on CPCK3, respectively. These adsorption curves are similar in shape. These curves rose steeply at the beginning of adsorption, and then more gradually. But the $q_{t}$ value of $p$-NP was the highest; that of $p$-CP, next; that of $p$-cresol, the least. These results agree with those reported earlier [26]. Fig. 5(d) shows the adsorption curves of $p$ $\mathrm{CP}$ on $\mathrm{CPKC} 2$, CPKC $3, \mathrm{CPKC} 4$, and $\mathrm{CPKC} 5$, respectively. The $q_{t}$ values increase with increased $\mathrm{KOH} /$ char ratios. Table 2 lists the results. The modeled results well agreed with the measured ones as shown in Fig. 5(a) and (d). The $r^{2}$ values were larger than 0.977 for the adsorption of $p$-NP, $p$-CP, $p$-cresol, MB, BB1, and AB74 on all carbons studied.

According to Eq. (7), $b$ and $t_{0}$ (thus, the initial rate $a$ ) can be obtained. Two points should be commented on. First, the assumption that $t \gg t_{0}$ is justified. Second, the $1 / b$ value obtained was larger with $\mathrm{KOH}$-activated carbon particularly for the adsorption of phenols. Such a trend is consistent with those found in conventional activated chemisorption that show that 
Table 3

Parameters of the Elovich equation for adsorption of dyes and phenols on various activated carbons at $30^{\circ} \mathrm{C}$

\begin{tabular}{lllllllr}
\hline Carbon & Solute & $1 / b\left(\mathrm{~mol} \mathrm{~kg}^{-1}\right)$ & $t_{0}\left(10^{-3} \mathrm{~h}\right)$ & $r^{2}$ & Solute & $1 / b\left(\mathrm{~mol} \mathrm{~kg}^{-1}\right)$ & $t_{0}\left(10^{-3} \mathrm{~h}\right)$ \\
\hline CPKC2 & MB & 0.186 & 3.83 & 0.990 & $p$-CP & 0.289 & 0.14 \\
CPKC3 & MB & 0.233 & 3.25 & 0.987 & $p$-CP & 0.299 & 0.10 \\
CPKC4 & MB & 0.245 & 0.42 & 0.979 & $p$-CP & 0.266 & 0.991 \\
CPCK5 & MB & 0.276 & 0.34 & 0.977 & $p$-CP & 0.264 & 0.988 \\
CPCK3 & AB74 & 0.059 & 4.78 & 0.989 & $p$-Cresol & 0.291 & 0.61 \\
CPCK3 & BB1 & 0.280 & 4.65 & 0.979 & $p$-NP & 0.334 & 0.24 \\
\hline
\end{tabular}

$1 / b$ is indicative of the number of sites available for adsorption [30]. Due to its nature, this equation predicts the behavior over the whole range of variable studied. This fact strongly supports its validity and suggests that the adsorption is ratedetermined by a chemisorption step [31,32]. Table 3 shows the adsorption $1 / b$ values of $\mathrm{BB} 1, \mathrm{MB}$, and $\mathrm{AB} 74$ on $\mathrm{CPKC} 3$, which are, respectively, $0.280,0.233$, and $0.059 \mathrm{~mol} \mathrm{~kg}^{-1}$. The $1 / b$ value of MB increased with increased $R_{\mathrm{KOH}}$ value. The $1 / b$ value is an indicator of adsorption rate. Regarding dye adsorption, the $1 / b$ values appeared to be lower for AB74 with larger molecules and CPKC2 with higher microporosity. The adsorption $1 / b$ values of $p$-NP, $p$-CP, and $p$-cresol on CPKC 3 are, respectively, $0.334,0.299$, and $0.291 \mathrm{~mol} \mathrm{~kg}^{-1}$; the differences are not large. The effect of the $R_{\mathrm{KOH}}$ value on the $1 / b$ value of $p-\mathrm{CP}$ is not significant. Note that the Elovich equation was derived from the chemisorption of gas onto solid surfaces, where
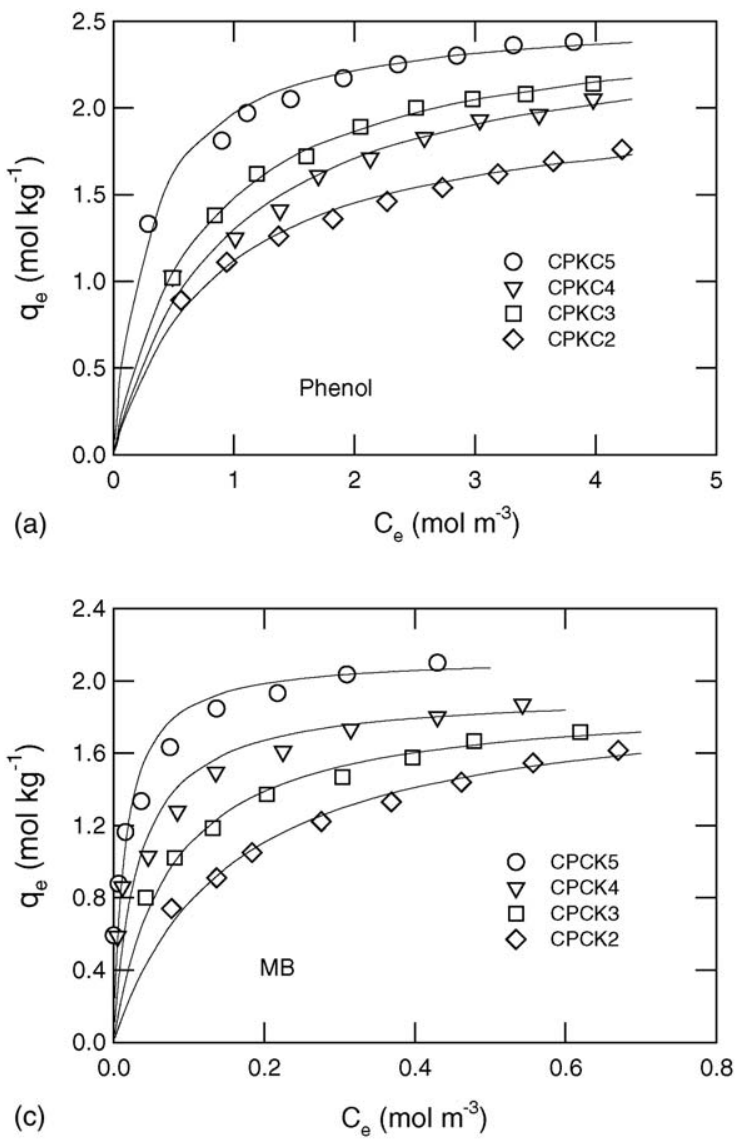

the rate-determining step involves the chemisorption. Thus, the adsorption process studied is to be regarded rather as a "chemical" than a "physical" process. The cane pith activated carbons were prepared by the $\mathrm{KOH}$ activation at $780^{\circ} \mathrm{C}$. The adsorption kinetics of dyes and phenols is suitably described using the Elovich equation, because carbons activated by $\mathrm{KOH}$ at $780^{\circ} \mathrm{C}$ have more functional groups than evidenced with temperature program desorption (TPD) [11]. The reason why the adsorption behavior is best described using the Elovich equation is because more functional groups are yet to be investigated.

\subsection{Equilibrium adsorption}

Fig. 6(a)-(d) show the typical equilibrium adsorptions of (a) phenol, (b) 4-CP, (c) $\mathrm{MB}$, and (d) $\mathrm{AB} 74$ at $30^{\circ} \mathrm{C}$ on the ACs prepared at a different $R_{\mathrm{KOH}}$. All curves rise steeply at
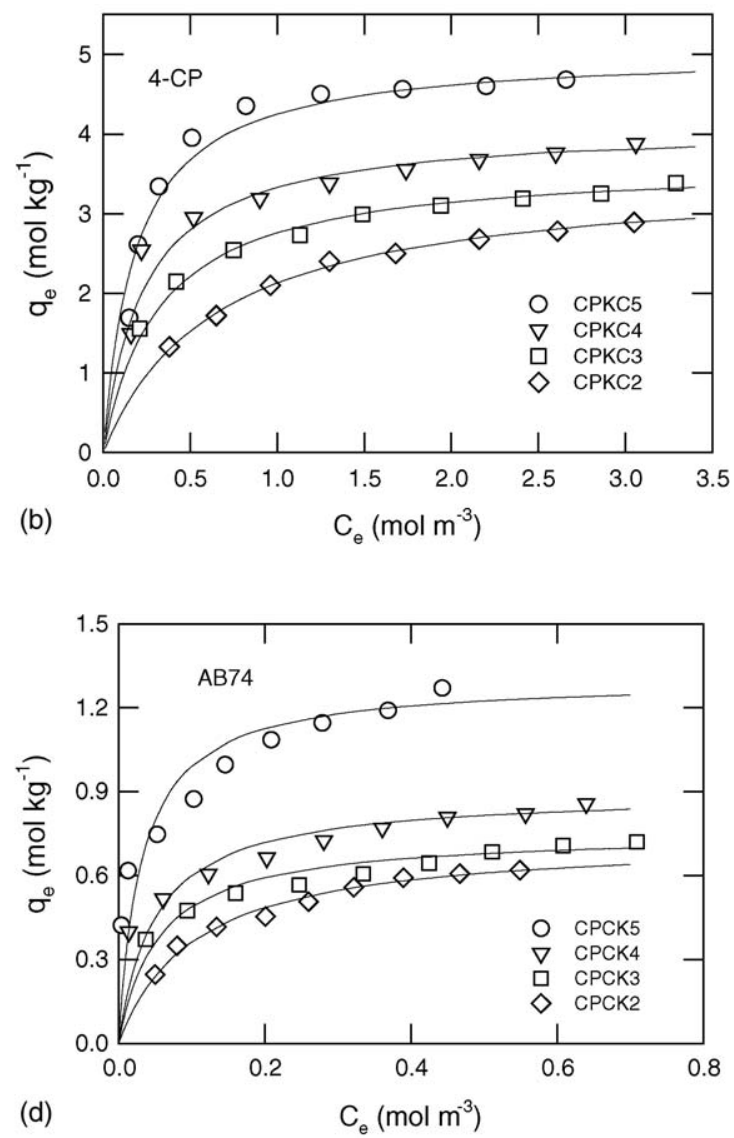

Fig. 6. Adsorption isotherms of (a) phenol, (b) 4-CP, (c) MB, and (d) $\mathrm{AB} 74$ at $30^{\circ} \mathrm{C}$ on the activated cane pith carbons with a $\mathrm{KOH} / \mathrm{char}$ ratio of $2(\mathrm{O}), 3(\nabla), 4(\square)$, and $5(\diamond)$. The curves were calculated using the Langmuir equation. Phenol and $p-\mathrm{CP}, C_{0}=5-0.5 \mathrm{~mol} \mathrm{~g}^{-1} ; \mathrm{MB}, C_{0}=1.5-0.15 \mathrm{~mol} \mathrm{~g}-1 ; \mathrm{AB}^{-}, C_{0}=1.0-0.1 \mathrm{~mol} \mathrm{~g}^{-1}$. 
Table 4

Parameters of the Langmuir equation and adsorbate area coverage in the adsorption of dye and phenol solutes on various activated carbons at $30^{\circ} \mathrm{C}$

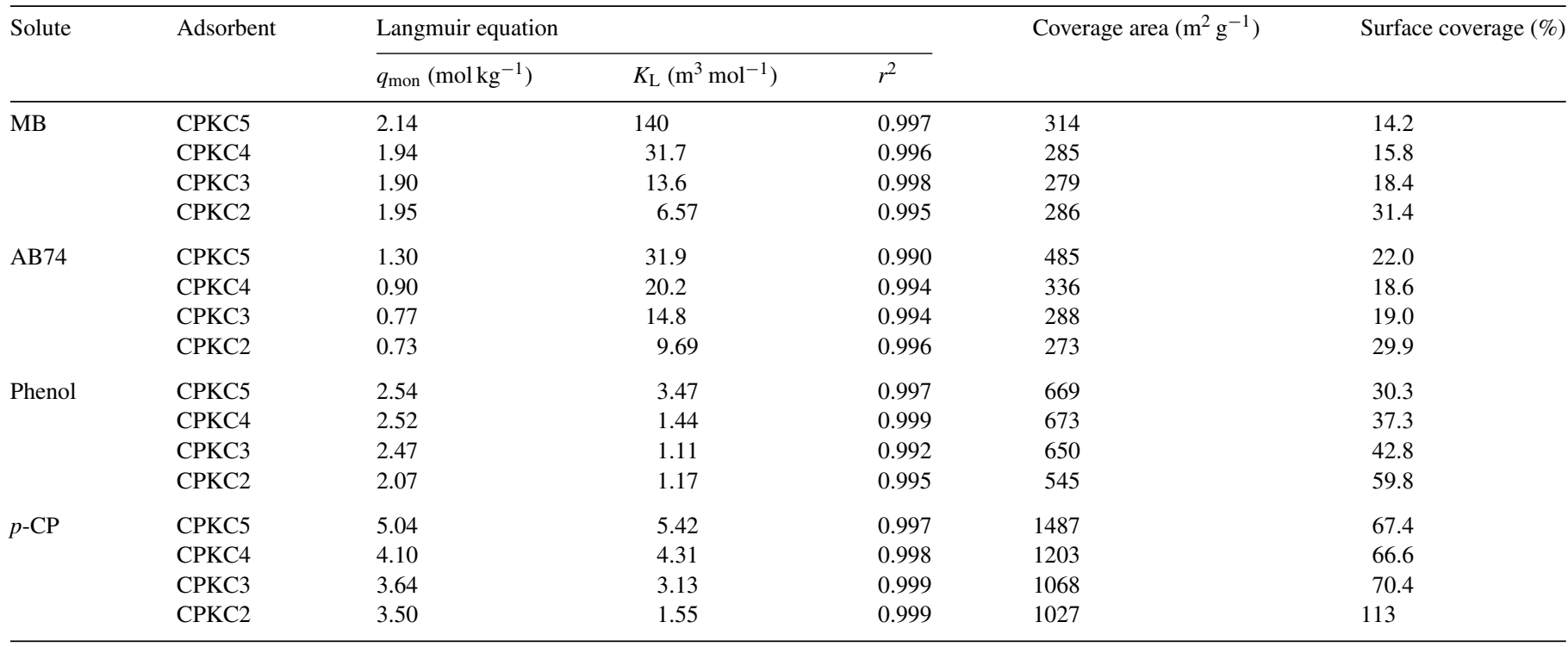

low concentration, and gradually approach a plateau at high concentrations. The correlation of isotherm data by theoretical or empirical equations is essential for practical operation. The widely used Langmuir equation is given as:

$\frac{C_{\mathrm{e}}}{q_{\mathrm{e}}}=\left(\frac{1}{K_{\mathrm{L}} q_{\mathrm{mon}}}\right)+\left(\frac{1}{q_{\mathrm{mon}}}\right) C_{\mathrm{e}}$

where $q_{\text {mon }}$ is the amount of adsorption (in $\mathrm{mol} \mathrm{kg}^{-1}$ ) corresponding to complete monolayer coverage and $K_{\mathrm{L}}$ is the Langmuir constant. Linear plots of $\left(C_{\mathrm{e}} / q_{\mathrm{e}}\right)$ against $C_{\mathrm{e}}$ (not shown) give $K_{\mathrm{L}}$ and $q_{\mathrm{mon}}$. In addition, the parameters (listed in Table 4) estimated from Fig. 6(a)-(d) are reliable since the fitting for $\mathrm{AB} 74, \mathrm{MB}, 4-\mathrm{CP}$, and phenol adsorptions on all ACs in the concentration range of study is excellent (correlation coefficient, $\left.r^{2}>0.984\right)$. Chemical activation with $\mathrm{KOH}$ is known to promote activated carbons with very high surface areas and predominance of micropores, which generally favor adsorption of small molecules. The adsorption $q_{\text {mon }}$ values of the activated carbons on phenol and 4-CP in this study proved this fact. The intended application of the activated carbons from cane pith is to remove organic species from wastewater (liquid-phase application) (Fig. 7).

Though the surface area of CPKC5 is 2.42 times that of CPKC2, $q_{\text {mon }}$ of CPKC5 to MB, phenol, 4-CP, and AB74 are, respectively, only $1.16,1.23,1.41$, and 1.78 times those of CPKC2. The differences between surface area ratio and $q_{\text {mon }}$ ratio of both carbons will be discussed in the following section under "surface coverage".

\subsection{Surface coverage}

Comparisons of adsorption characteristics for adsorbents of various surface areas or void structures on various adsorbates by surface coverage are helpful in understanding the interaction between adsorbates and the surfaces of adsorbents, thus facili- tating the design and preparation of adsorbents which meet the requirements of the adsorbates [33].

An adsorbate forms a monolayer cover on the surface of an AC. Based on the covered mass $\left(q_{\text {mon }}\right)$, calculated with the Langmuir equation and the projected area of an adsorbate molecule, the adsorbate coverage per unit gram of activated carbon $\left(S_{\mathrm{c}}\right.$, $\mathrm{m}^{2} \mathrm{~g}^{-1}$ ) can be calculated using the following equation:

$S_{\mathrm{c}}=\frac{6.023 \times 10^{23} \times A_{\mathrm{m}} \times q_{\mathrm{mon}}}{1000}$

The value of projected area $A_{\mathrm{m}}$ of phenol, $p-\mathrm{CP}, \mathrm{MB}$, and AB74 were $0.437,0.487,0.244$, and $0.64 \mathrm{~nm}^{2}$, respectively [27]. In addition, the surface coverage is defined as the ratio of $S_{\mathrm{c}}$ to BET surface area of the $\mathrm{AC}\left(S_{\mathrm{c}} / S_{\mathrm{p}}\right)$, and the calculated results are listed in Table 4 . The $S_{\mathrm{c}} / S_{\mathrm{p}}$ values of MB and AB74 were from 14.2 to $31.4 \%$ and from 18.6 to $29.9 \%$, respectively, and

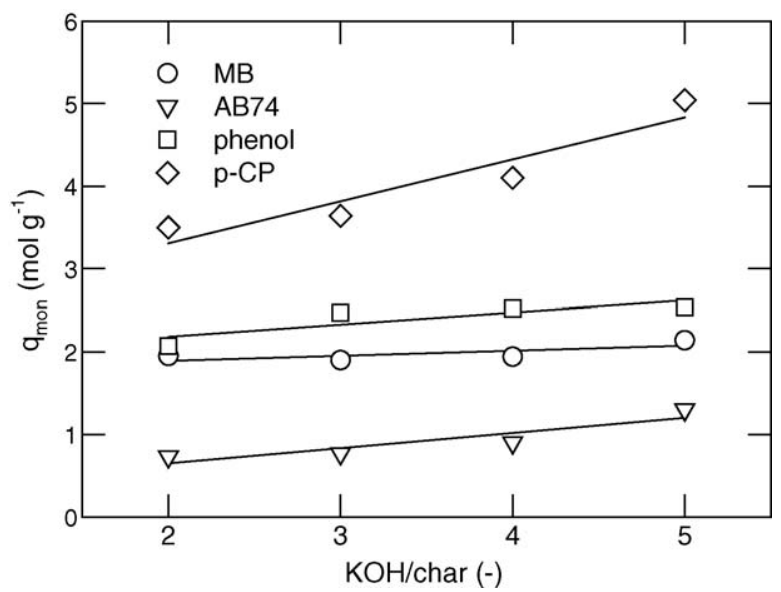

Fig. 7. The amount of adsorption corresponding to complete monolayer coverage of $\mathrm{MB}(\bigcirc)$, $\mathrm{AB} 74(\nabla)$, phenol $(\square)$, and $p$-CP $(\diamond)$ on the activated cane pith carbons prepared with different $\mathrm{KOH} / \mathrm{char}$ ratios. 
Table 5

Literature values of covered areas for the adsorption of dye and phenol solutes on various activated carbons

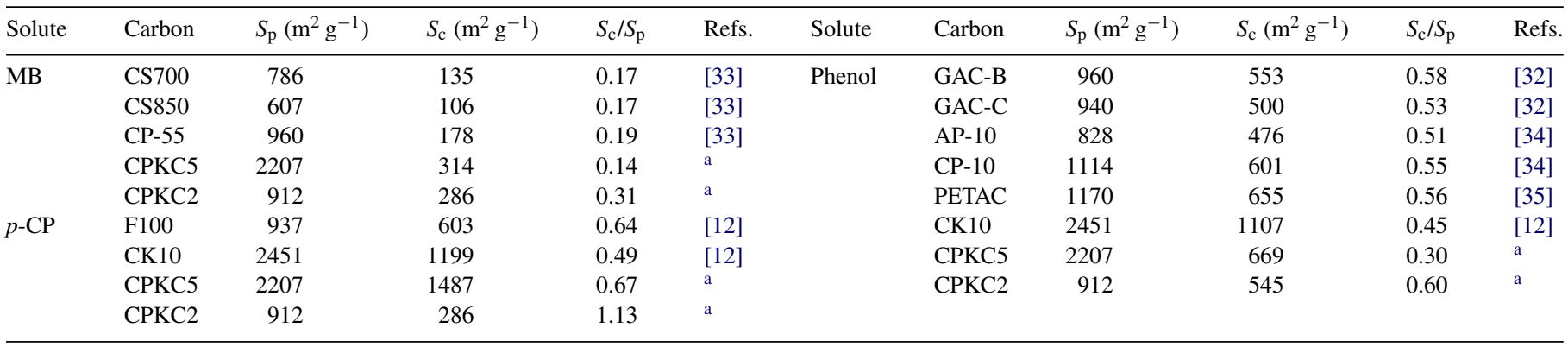

a This work.

lower than those of phenol and $p$-CP, which were from 30.3 to $59.8 \%$ and from 66.6 to $113 \%$, respectively.

Table 5 lists the surface coverage of phenols and dyes on various carbons as reported in the literature. Data of BET surface areas and $q_{\text {mon }}$ for phenol, $p$-CP, and $\mathrm{MB}$ on various activated carbons were collected [12,33-35]. These activated carbons were either commercial products or made by researchers, the characteristics of which were better than commercial ones. The largest $q_{\text {mon }}$ value in the literature was selected for calculation of various $S_{\mathrm{c}}$ values according to Eq. (9). The results are shown in column 4 of Table 5 , because $q_{\text {mon }}$ value was constant in every adsorption equilibrium system, unaffected by any operation factors. Via $q_{\text {mon }}$, the derived $S_{\mathrm{c}} / S_{\mathrm{p}}$ values (covered area per surface area) can be utilized for the comparisons of the characteristics of various activated carbons.

The surface coverage of phenol is from 45 to $58 \%$; those of $p$-CP, from 49 to $64 \%$; those of MB, 17 and $19 \%$. The $S_{\mathrm{c}} / S_{\mathrm{p}}$ values of $\mathrm{CPKC} 3, \mathrm{CPKC} 4$, and $\mathrm{CPKC} 5$ of this study are within the range reported in the literatures; but that of CPKC2 is much higher. SEM observation of CPKC2 revealed that the openings of the honeycomb holes looked like those of porous sponge. Whether it was related to the high $S_{\mathrm{c}} / S_{\mathrm{p}}$ value is worthy of further study for the design and preparation of high $S_{\mathrm{c}} / S_{\mathrm{p}}$ activated carbons.

\section{Conclusions}

In this study, high surface area activated carbons (912-2299 $\mathrm{m}^{2} \mathrm{~g}^{-1}$ ) were successfully prepared from cane pith by $\mathrm{KOH}$ activation, a chemical method. Activated carbons prepared from $\mathrm{KOH} / \mathrm{char}$ at weight ratios of 2-5 had of same characteristics as microporous carbons; the activated carbon with a $\mathrm{KOH} / \mathrm{char}$ ratio of 6 had the same characteristics as both mesoporous and microporous carbons. In the adsorption kinetics of the adsorbate dyes (BB1, MB, and AB74) and phenols ( $p$-cresol, $p$-CP, and $p$-NP), the $q_{t}$ values rose steeply at the beginning, and gradually approached a plateau. This phenomenon was suitably analyzed with the Elovich equation, which described the chemical adsorption. All isotherm equilibrium curves of the adsorbate dyes (MB and AB74) and phenols (phenol and $p-\mathrm{CP}$ ) rose steeply at low concentrations, and gradually approached a plateau at high concentrations well described with the Langmuir equation. SEM observation revealed that the hole openings of the activated carbons with a $\mathrm{KOH} / \mathrm{char}$ ratio of 2 made it look like porous sponge; and the $S_{\mathrm{c}} / S_{\mathrm{p}}$ values of the activated carbons were, respectively, 31.4\% (MB), 29.9\% (AB74), 59.8\% (phenol), and $113 \%$ ( $p-\mathrm{CP})$, studied in this research. The adsorption capacities per unit surface area of the activated carbons were especially high.

\section{Acknowledgment}

Financial support for this work by the National Science Council, Taiwan, under Grant NSC92-2211-E-239-006 is gratefully acknowledged.

\section{References}

[1] C. Ng, J.N. Losso, W.E. Marshall, R.M. Rao, Bioresource Technol. 84 (2002) 177.

[2] R.S. Juang, R.L. Tseng, F.C. Wu, Adsorption 7 (2001) 65.

[3] W.T. Tsai, C.Y. Chang, M.C. Lin, S.F. Chien, H.F. Sun, M.F. Hsieh, Chemosphere 45 (2001) 51.

[4] R.L. Tseng, F.C. Wu, R.S. Juang, Carbon 41 (2003) 487.

[5] W.T. Tsai, C.Y. Chang, S.L. Lee, Carbon 35 (1997) 35.

[6] H. Fujimoto, A. Mabuchi, K. Tokumitsu, T. Kasuh, Carbon 38 (2000) 871.

[7] K. Kinoshita, Carbon, Electrochemical and Physicochemical Properties, Wiley, New York, 1988.

[8] F.C. Wu, R.L. Tseng, R.S. Juang, J. Hazard. Mater. B69 (1999) 287.

[9] R.S. Juang, F.C. Wu, R.L. Tseng, J. Colloid Interf. Sci. 227 (2000) 437.

[10] F.C. Wu, R.L. Tseng, C.C. Hu, C.C. Wang, J. Power Sources 138 (2004) 351.

[11] F.C. Wu, R.L. Tseng, C.C. Hu, C.C. Wang, J. Power Sources 144 (2005) 302.

[12] Z. Hu, M.P. Srinivasan, Micropor. Mesopor. Mater. 27 (1999) 11.

[13] K.S.W. Sing, D.H. Everett, R.A.W. Haul, L. Moscou, R.A. Pierotti, J. Rouquerol, Pure Appl. Chem. 57 (1985) 603.

[14] G. Amarasekera, M.J. Scarlett, D.E. Mainwaring, Carbon 36 (1998) 1071.

[15] M.A. Lillo-Rodenas, D. Cazorla-Amoros, A. Linares-Solano, Carbon 41 (2003) 267.

[16] F. Rouquerol, J. Rouquerol, K. Sing, Adsorption by Powers and Porous Solids: Principles, Methodology and Applications, Academic Press, London, 1999.

[17] R.S. Juang, F.C. Wu, R.L. Tseng, Colloids Surf. A: Physicochem. Eng. Asp. 201 (2002) 191.

[18] Z. Hu, M.P. Srinivasan, Micropor. Mesopor. Mater. 43 (2001) 267.

[19] M.S. El-Geundi, Adsorpt. Sci. Technol. 15 (1997) 777.

[20] K. Gergova, N. Petrov, V. Minkova, J. Chem. Technol. Biotechnol. 56 (1993) 78 .

[21] F. Julien, M. Baudu, Water Res. 32 (1998) 3414. 
[22] Z. Hu, E.F. Vansant, Micropor. Mater. 3 (1995) 603

[23] B.S. Girgis, S.S. Yunis, A.M. Soliman, Mater. Lett. 57 (2002) 164.

[24] Z. Hu, H. Guo, M.P. Srinivasan, N. Yaming, Separ. Purif. Technol. 31 (2003) 47.

[25] N. Tancredi, T. Cordero, J. Rodriguez-Mirasol, J.J. Rodriguez, Fuel 75 (1996) 1701.

[26] R.L. Tseng, S.K. Tseng, J. Colloid Interf. Sci. 287 (2005) 428.

[27] F.C. Wu, R.L. Tseng, C.C. Hu, Micropor. Mesopor. Mater. 80 (2005) 95.

[28] T. Otowa, Y. Nojima, T. Miyazaki, Carbon 35 (1997) 1315.

[29] J.L. Figueiredo, M.F.R. Pereira, M.M.A. Freitas, J.J.M. Orfao, Carbon 37 (1999) 1379.
[30] C. Aharoni, F.C. Tompkins, Kinetics of adsorption and desorption and the Elovich equation, in: D.D. Eley, H. Pines, P.B. Weisz (Eds.), Advance in Catalysis and Related Subjects, vol. 21, Academic Press, New York, 1970.

[31] C.W. Cheung, J.F. Porter, G. McKay, Water Res. 35 (2001) 605.

[32] R.S. Juang, M.L. Chen, Ind. Eng. Chem. Res. 36 (1997) 813.

[33] C.T. Hsieh, H. Teng, Carbon 38 (2000) 863.

[34] A.-N.A.M. El-Hendawy, S.E. Samra, B.S. Girgis, Colloids Surf. A: Physicochem. Eng. Asp. 180 (2001) 209.

[35] C. Moreno-Castilla, J. Rivear-Utrilla, M.V. Lopez-Ramon, F. CarrascoMarin, Carbon 33 (1995) 845. 